\title{
Craniofacial Changes in Children-Birth to Late Adolescence
}

\author{
A. Midori Albert*, Amanda L. Payne, Sean M. Brady, Charissa Wright \\ University of North Carolina Wilmington, Institute for the Interdisciplinary Study of Identity Sciences, 601 S. \\ College Road, Wilmington, North Carolina, USA, 28403
}

\author{
*Corresponding Author: A. Midori Albert, University of North Carolina Wilmington, Institute for the \\ Interdisciplinary Study of Identity Sciences, 601 S. College Road, Wilmington, North Carolina, USA, \\ Email: albertm@uncw.edu
}

\begin{abstract}
Previous studies encompassing variation within the craniofacial complex have been conducted on separate components of the face. However, to date, lacking is a holistic description of how the juvenile craniofacial complex changes from infancy to adulthood that includes separate components in relation to the entirety of the face. Much of the current literature provides highly detailed information on growth and development of separate components. The purpose of this research was to impart an in depth understanding of juvenile craniofacial growth and development such that the distilled information may be utilized in the forensic sciences to further technologies concerning age-progression/regression, computer automated face recognition, and identification. This study involved a literature review, analysis, and consolidation of information, fromseparate facial components relative to the entirety of the face, into a singular paper. Results yielded103 sources, derived from 57 search iterations that initially provided 4898 articles. These 103 sources, recognized as highly relevant, were analyzed further. Results of this analysis indicated that about 20 final articles provided the most complete information for a thorough understanding of craniofacial morphological growth and development from birth through maturation, and are explained and summarized in this paper.
\end{abstract}

Keywords: Craniofacial age-related changes, craniofacial growth and development, craniofacial changes as a biometric, computer automated face recognition, identity sciences.

\section{INTRODUCTION}

The purpose of this research was to delve into the published literature to mine data on the growth, development, and maturation of the craniofacial complex in children, specifically in females and males of various populations from birth to late adolescence (roughly 18 years of age). The goal was to capture information on the developmental rate and pattern of facial skeletal and soft tissue changes in children, and to construct an overall picture of the general face shape changes that occur. This research investigated if such a pattern could be found and or determined based on previous biomedical, anatomical and dental research that was inclusive of such growth phenomena.

Inasmuch as there is a paucity of published literature on studies that may be have been conducted with the direct aim of determining facial growth trajectories as an end result, the information reported here is an amalgamation of data extrapolated from multiple publications addressing diverse features of the skull and face, that incorporated growth changes as part of a bigger goal, typically one involving oralmaxillary facial surgery techniques, or cranial or facial plastic surgery approaches to correct abnormalities or injuries, and so forth.

To overcome the limitation of scant literature on the topic of craniofacial morphological changes in children specifically, our approach was to divide the skull and face into component parts and conduct multiple iterations of literature searches using numerous derivative terms relating to growth, development, and maturation of the bones and soft tissues of the face, explained further later. Reported here are the findings from a wide-cast net of literature searches resulting in nearly 5,000 sources, narrowed to about 50 of the most relevant publications, from the most recent ten years, 2010-2017, for which an extensive review shaped the outcomes detailed in the following sections (i.e., the results that follow).

\section{MeTHODS}

\subsection{Approach}

The method of data collection for this project was to (1) generate lists of pertinent operative 
keywords and phrases targeted toward the subject matter, (2) execute searches of the library databases indexing the known published literature, where publications matching the keywords and phrases were identified, (3) probe the voluminous (often several thousand) items returned from the various searches to detect the pertinent studies, (4) review the finds and further narrow the publications to those most informative to our goal (i.e., those sources that provided factual information about craniofacial skeletal and soft tissue age-related changes between birth and late adolescence), (5) generate the final list of references and retrieve the publications, from which we (6) read, examined, and analyzed content to cull and synthesize the age-related information, and finally (7) report here, in a simulated diachronic fashion to capture as much of the known - not merely anecdotally observed-growth, development, and morphological change as possible that reflects what may be evidenced in most normal, healthy individuals spanning diverse populations including both sexes. This methodological approach is consistent with the Cochrane criteria [1], which provides the "gold standard" for systematic literature reviews.

\subsection{Data and Analysis}

Data for this research were obtained from the retrieved publications, dissected to determine the essential skeletal and soft tissue facial morphology information contained within. We sought information on the types of change, the nature of the change, and timing of the change that occurs as individuals grow. The method of gaining this understanding involved piecing together isolated bits of growth information from the various facial components often addressed separately and from a multitude of different sources (i.e., different studies on different samples of different ages focused on different features of the head and face). This in a sense was our data analysis. Our results are basically the compilation of the analyzed data into a unified explication of how an individual child's face-female or male, of any population-would be expected to change in appearance over the span of his or her childhood into young adulthood.

\section{Results}

\subsection{Literature Searches}

Appendix A comprises the list of the aforementioned keywords and phrases identified and used to retrieve the literature cited in this report, as well as the number of search results pulled from the review of the literature and deemed relevant to this research. Appendix B contains the breakdown of the search iterations listed by author names and years of publication, based on different regions of the face (i.e., mandible, maxilla, orbits, nasal, cranial width, face height, forehead, and total face). Below, we now report, explain and discuss the results of the data extricated from the published literature. We begin with an overview of craniofacial landmark terminology, which will help clarify the various facial dimension changes that occur as children grow and mature. Following that, the progress of craniofacial maturation will be explained, first as separate facial components, then as a whole as best as can be relayed.

\subsection{Facial Geometry}

The human face has well defined planes, areas and landmarks. There are four distinct planes, shown in Figure 1, and defined as:

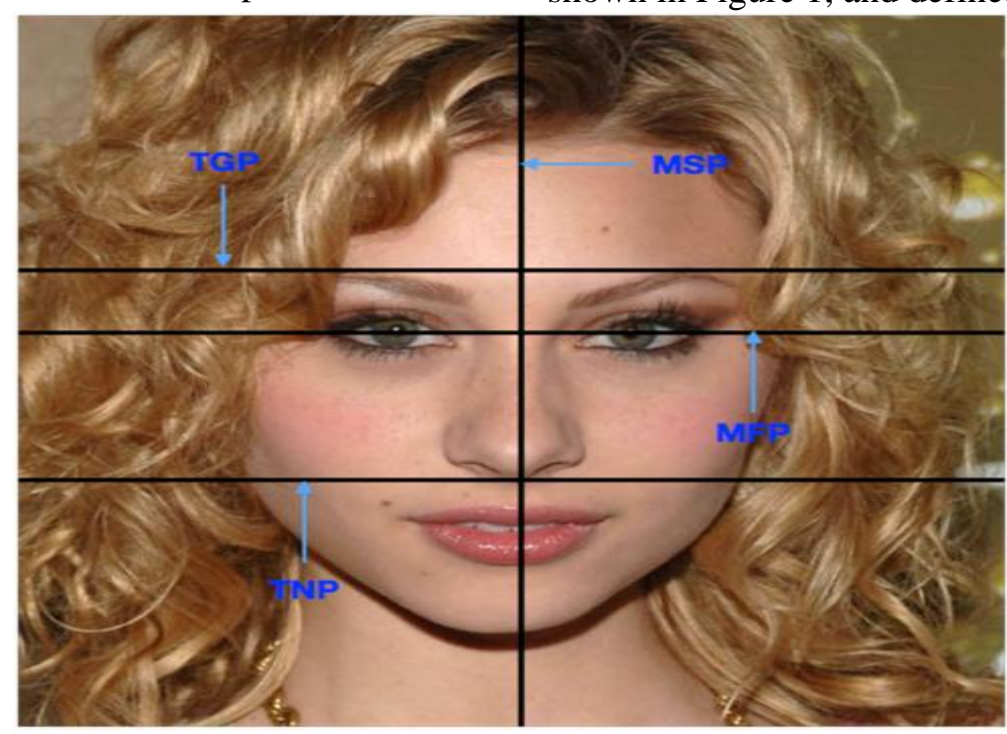

Figure1: Four Facial Planes 
1. Midsagittal plane (MSP): the midline of the face; divides the face bilaterally into left and right sides.

2. Midfacial Plane (MFP): divides the face into inferior and superior (or lower and upper) halves.

3. Transverse nasal plane (TNP): the horizontal plane parallel to MFP.

4. Transglabellar plane (TGP): parallel to the TNP and the MFP passing through the glabella.

The frontal view of the face has eight distinct areas as shown in Figure 2. The different areas are the frontal area, nasal area, labial area, mental area, orbital area, zygomaxillary area, buccomandibular area and auricular area (ear region, not visible in Fig. 2). Each facial area has a set of anthropometric points/landmark points associated with it. Anthropometric points are also referred to as craniofacial landmarks, and are often used to standardize measurementtaking. The landmarks common to soft tissue and hard tissue studies are comparable. Figure 3 depicts a right lateral and anterior (frontal) view of a face with landmarks labeled on soft tissue and underlying hard tissue areas, with the full landmark terminology below that. Table 1, which follows Figure 3, provides definitions for various landmarks.

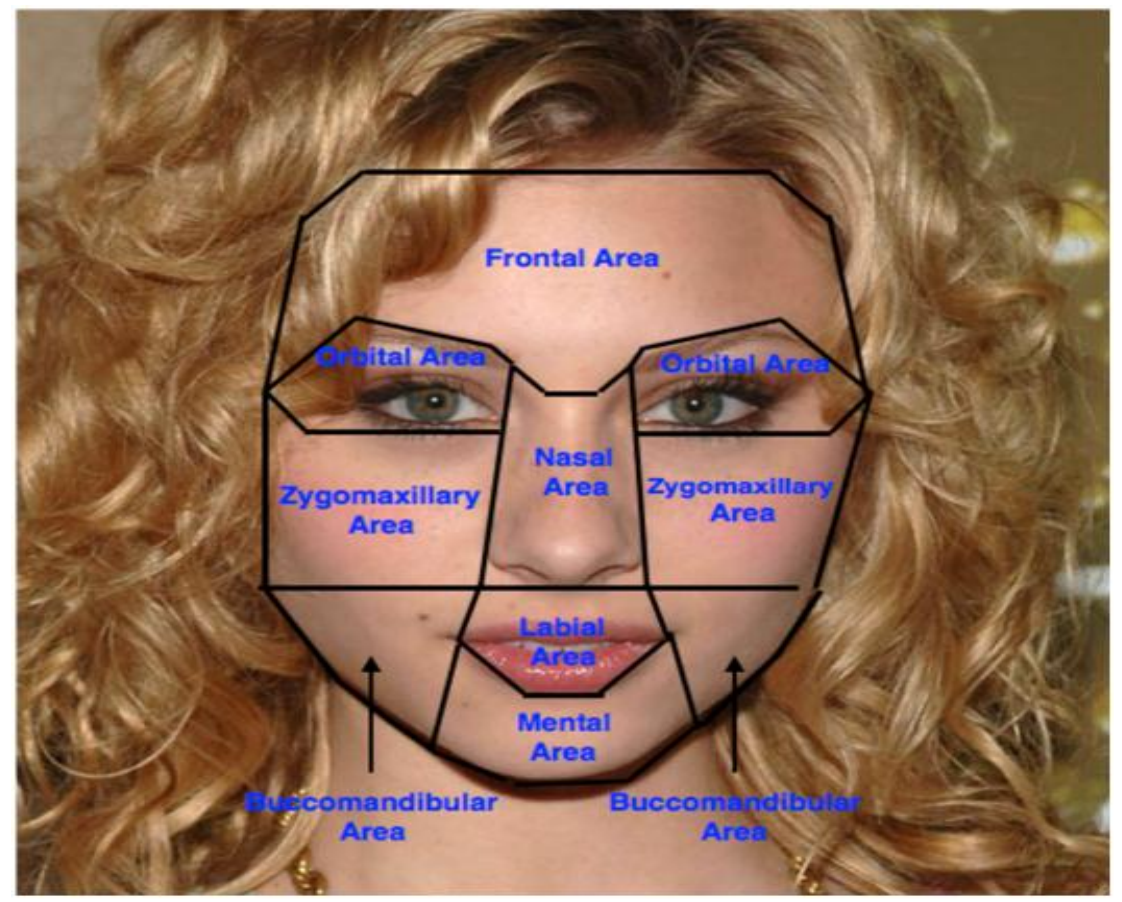

Figure2: Eight Facial Areas

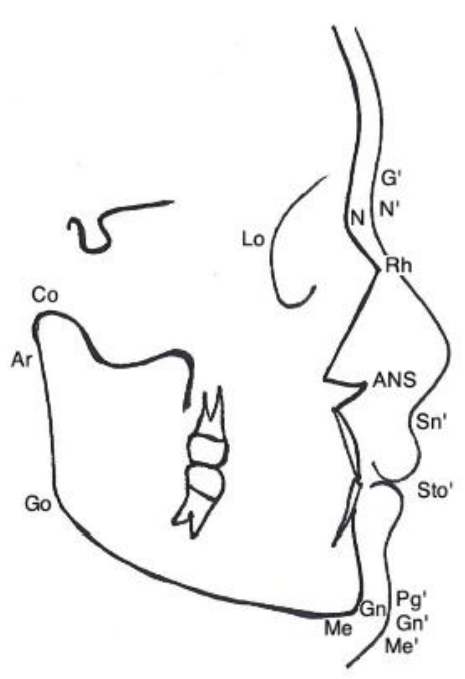

Skeletal Landmarks

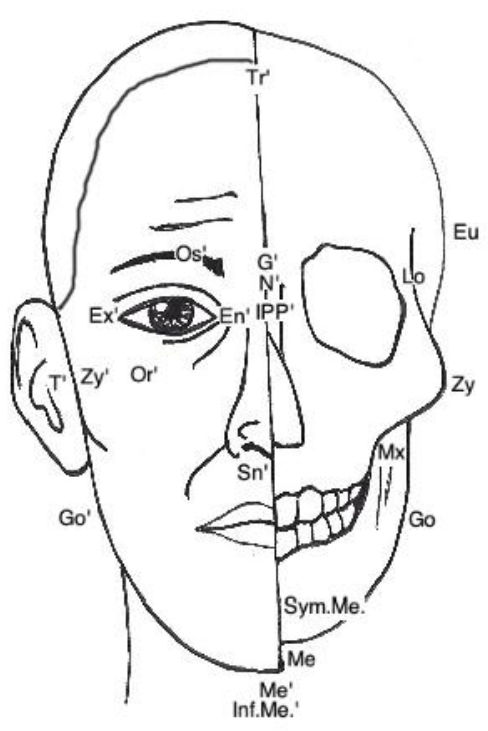

Soft Tissue Landmarks

Figure3: Skeletal and Soft Tissue Reference Guide 


\begin{tabular}{|c|c|c|c|}
\hline ANS & Anterior Nasal Spine & En’ & Endocanthion \\
\hline $\mathrm{Ar}$ & Articulare & Ex' & Exocanthion \\
\hline $\mathrm{Co}$ & Condylion & $\mathrm{G}^{\prime}$ & Glabella \\
\hline $\mathrm{Eu}$ & Euryion & Gn’ & Gnathion \\
\hline $\mathrm{Gn}$ & Gnathion & Go’ & Gonion \\
\hline Go & Gonion & Inf.Me' & Inferior Menton margin \\
\hline Lo & Lateroorbital & IPP' & Interpupillar Plane \\
\hline $\mathrm{Me}$ & Menton & Me' & Menton \\
\hline $\mathrm{Mx}$ & Maxilla & $\mathrm{N}^{\prime}$ & Nasion \\
\hline $\mathrm{N}$ & Nasion & Os' & OrbitaleSuperius \\
\hline $\mathrm{Rh}$ & Rhinion & Or' & Orbitale \\
\hline Sym.Me & Symphysis Menti & $\mathrm{Pg}{ }^{\prime}$ & Pogonion \\
\hline \multirow[t]{4}{*}{$\mathrm{Zy}$} & Zygoma & Sn’ & Subnasale \\
\hline & & Sto' & Stomion \\
\hline & & $\mathrm{T}^{\prime}$ & Tragus \\
\hline & & Tr' & Trichion \\
\hline
\end{tabular}

Table1: Description of Anthropometric Points

\begin{tabular}{|l|l|}
\hline \multicolumn{1}{|c|}{ Landmark Name } & \multicolumn{1}{c|}{ Landmark Description } \\
\hline Glabella & Smooth area between the eyebrows just above the nose \\
\hline Sublabiale & Determines the lower border of the lower lip and the upper border of the chin. \\
\hline Pogonion & The most anterior midpoint of the chin. \\
\hline Endocathion & The medial corner of the eye \\
\hline Exocathion & The lateral corner of the eye \\
\hline Pupil & Is the center of the iris of the eye \\
\hline PalbebraleInferius & The lowest point in the mid portion of the free margin of each lower eyelid \\
\hline Sellion & The deepest landmark located in the bottom of the nasofrontal angle. \\
\hline Pronasale & The most protruded point of the apex nasi \\
\hline Alare & The most lateral point of each alare contour \\
\hline Highest point of columella prime & The point on each columella crest,level with the tip of the corresponding nostril. \\
\hline LabialeSuperius & The midpoint of the upper vermillion line. \\
\hline Labialeinferius & The midpoint of the lower vermillion line. \\
\hline Stomion & The intersection of the MSP with the labial fissure. \\
\hline Cheilion & The corner of the mouth. \\
\hline Superaurale & The highest point on the free margin of the auricle. \\
\hline Subaurale & The lowest point on the free margin of the ear lobe. \\
\hline Postaurale & The most posterior point on the free margin of the ear. \\
\hline Otobasioninferius & The point of attachment of the ear lobe to the cheek. \\
\hline
\end{tabular}

\subsection{The Progress of Craniofacial Maturation}

Following is a discussion of the facial shape and size changes that occur from birth through late adolescence. Information is relayed as much as possible in a synergistic way, rather than piecemeal. However, as growth velocities vary in different parts of the face, some of the information provided below is listed separately rather than depicted as a fluid process, which is elusive and difficult to capture due to its highly variable nature. As such, the craniofacial complex is divided into nine separate components (in a relative superior to inferiortop down - orientation): orbit, nasal, maxilla and mandible, followed by the facial planes and head and face overall.

\subsection{Orbit}

The orbit is composed of seven bones: the orbital process of the frontal bone, the lesser wing of the sphenoid bone, the orbital palate and frontal process of the maxilla, the zygoma, the orbital palate of the Palatine bone, the lacrimal bone, and the lamina papyracea of the ethmoid bone [2]. Most of the orbital growth that occurs happens because of the different sutures between the multiple bones [3].

The orbits are rather large early on in growth and development compared to the rest of the face due to the rapid growth of the eyes in the first year of life [3-4]; the growth statistics from each of the different portions covered provide a picture of near complete growth between ages 5 and 8 years.

This section is broken into orbital height, intercanthal width, width, and orbital volume to get a better grasp on growth of the orbital region. For a visual of each orbital component, see Figure 4. 

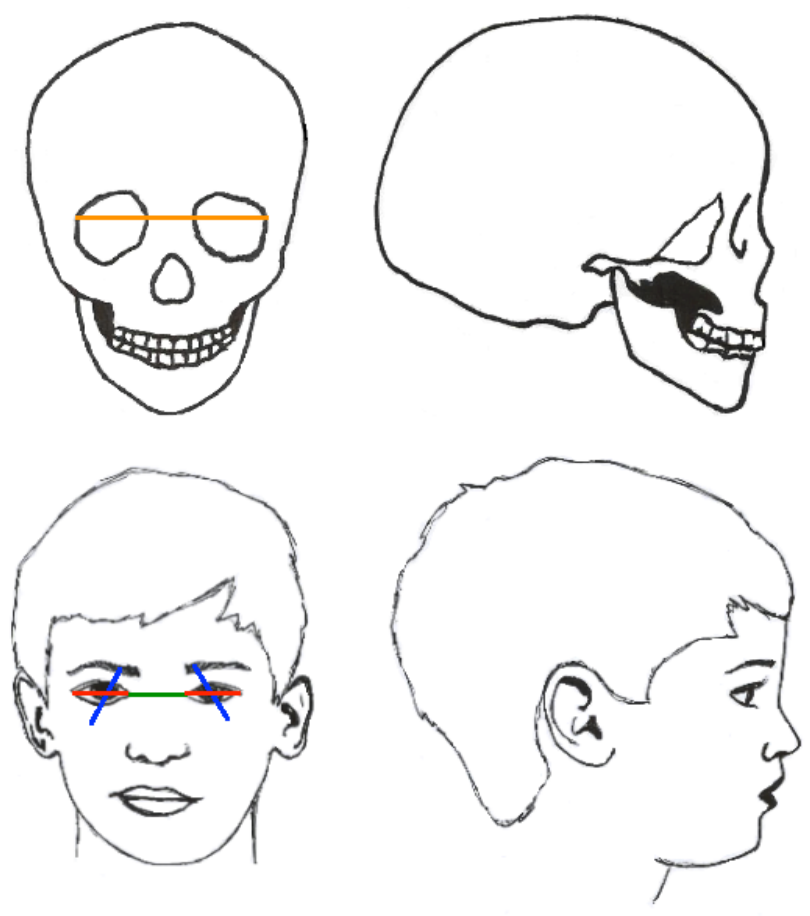

Figure4: Orbital Components (contains images modified from [18, 41])

\begin{tabular}{|l|l|l|}
\hline Color Code & Facial Component & Section \\
\hline & Orbital Height & 3.3 .1 \\
\hline & Intercanthal Width & 3.3 .2 \\
\hline & Orbital Width & 3.3 .3 \\
\hline & Lateral Orbital Width & 3.3 .3 \\
\hline
\end{tabular}

\subsubsection{Orbital Height}

Orbital height is measured from Orbital to Orbital Superius (Or'-Os') (See Figure 3). Costello et al. [3] state that orbital height is different than most other orbital dimensions in that it has a more gradual growth rate compared to the width and volume. Orbital height at 4.5 years is $78 \%$ of its adult size [5]. It gains $10 \%$ growth in the next two years, attaining around $88 \%$ of its adult size by 6.5 years [5]. Around 10.5 years, females have achieved $96 \%$ of their total growth while males are lagging at $91.5 \%$, which is congruent with male-female growth patterns [5].

\subsubsection{Intercanthal Width}

Intercanthal width is measured from Endocanthion of the left eye to Endoocanthion of the right eye (En'-En') (See Figure 3). Intercanthal width is averaged at $93 \%$ of adult growth in both sexes around age 5 years $[3,5]$. However, females are consistently very high $(98 \%)$ in their adult size from age 4 years onward; males have a later maturation age around 10.5 years of age [3, 5-7].

\subsubsection{Orbital Width}

Orbital Width is measured from Endocanthion to Exocanthion (En'-Ex') (See Figure 3). Orbital width is stated at being $70 \%$ of its adult size at .9 years (Humphrey, 1998). It attains $90 \%$ of its adult size around 7.5 years [5-6, 8]. Another orbital width (lateral) is measured from Lateroorbital of the left eye to Latero-orbital of the right eye (Lo-Lo) (See Figure 3). Between 5 to 14 years of age, this lateral skeletal width only grows about $4 \mathrm{~mm}$, congruent with craniofacial growth patterns of swift early growth and subsequent passive growth until puberty[9].

\subsubsection{Orbital Volume}

Costello et al. [3] reference that the most rapid growth occurs in the first year of life with a decreasing velocity over the next 5 years. This coincides with Berger's [2] assessment that 50\% of the volume growth occurs in the first 2 years of life; with the assertion that Yang et al. [10]make that the orbit grows most rapidly from birth to 3 years; and with Boyette's[11] assessment that there is rapid growth until age 5 years. These affirmations paint a picture of amazing growth up until 5 years of age. The numbers indicate that at age 3 years, $69 \%$ of adult size is attained and that at 5 years most of the growth is complete with orbital volume reaching $90 \%$ of its adult size (as an aside, it should be noted that Yang et al. [10] displayed that only $75 \%$ of adult size was attained at age 5 
years) [3, 11]. Orbital volume attains its adult dimension at around 7 years of age [2].

\subsection{Nasal}

The nasal bones are two small, paired bones that are set between the orbits, maxilla, and frontal bone. Nasal bone growth is measured from Nasion to Rhinion $(N-R h)$ (See Figure 3; for a visual nasal component, See Figure 5). Very little has been written on the nasal bone and future literature could be very useful. The nasal bone growth processes are not sexually dimorphic. However, between the ages of 19 and 20 years, sex differences appeared; after that point, male nasal bone length is noticeably longer than those in females (Males: $20.97300 \pm 2.7285 \mathrm{~mm}$; Females: $18.6100 \pm$ $1.9284 \mathrm{~mm}$ ) [12]. Park et al. [12] also specifies that between ages 3 to 4 years and 11 to 12 years, significant growth spurts occur.
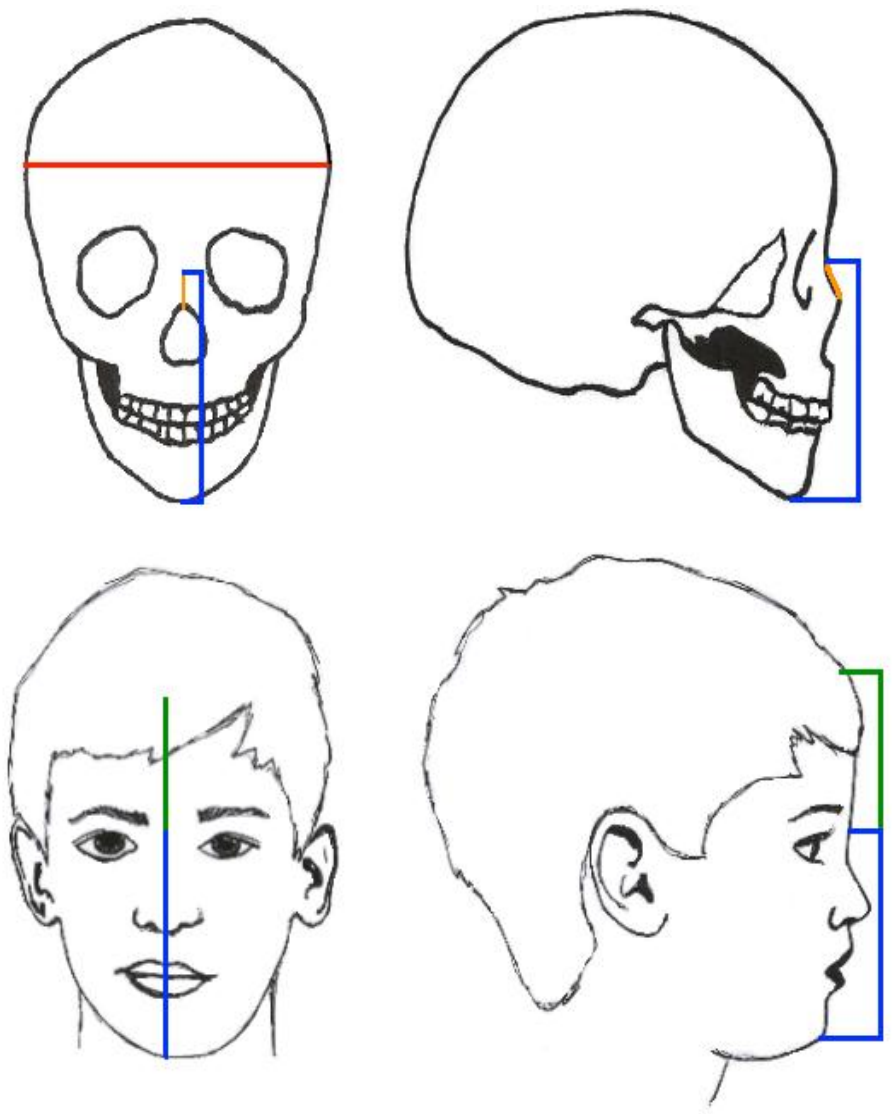

Figure5: Miscellaneous Components (contains images modified from [18, 41]

\begin{tabular}{|l|l|l|}
\hline \multicolumn{1}{|c|}{ Color Code } & \multicolumn{1}{|c|}{ Facial Component } & \multicolumn{1}{|c|}{ Section } \\
\hline & Nasal Bone & 3.4 \\
\hline & Cranial Width & 3.7 .1 \\
\hline & AFH & 3.7 .2 \\
\hline & Forehead Height & 3.7 .3 \\
\hline
\end{tabular}

Nasal bone length, apart from the ages of 11 to 15 years, is positively correlated to nasal height and the length of the nasal bridge [12]. However, the external soft-tissue continues to grow all throughout life [13]. Chen et al. [14]acknowledge that after 24 years of age the soft tissue profile relatively stabilizes and "becomes more constant." This soft tissue complication does not stop there though; ethnicity plays a very significant role in the nasal profile, increasing the difficulty of an average database for nasal profiling [14].

Sun et al.[15]observed no significant differences between the upper airway development in males and females until 13 years of age. The sagittal nasopharyngeal airway space is increasing during 5 to 10 years of age, with rapid growth change of the upper airway from age 6 to 9 years.

\subsection{Maxilla}

Due to the fact that the maxilla is situated in the middle of the face, its growth and development is affected by the simultaneous growth of the surrounding bones. The lower orbital and nasal measurements of the maxilla will be discussed in their respective sections. This section will cover the anteroposterior length of the palate 
and the transverse and vertical sections of the maxilla. Let it also be noted that eruption of the second molars is a large contributing factor to maxillary growth and is averaged at 12 years of age in this assessment.

Overall, the maxilla grows in a forward and downward projection with steady/passive growth until age 5 years, where it is $85 \%$ of its eventual adult size $[3,16]$. The maxilla then increases its growth pace until age 11 years where growth plateaus until age 15 years [17].

The more rapid pace found in the 5 years to 11years age gap coincides with tooth eruption patterns; these patterns allow for a strong prediction of adult size at age 12 years, especially in light of Ferguson's [18] concept on structural-counterpart relationship [17]. This is also enforced by the relatively easy rapid maxillary expansion up to age 10 years [19]. Average total maxilla maturation is age 14 years in females and 15 years in males [3]. For a visual of each maxillary component, see Figure 6.
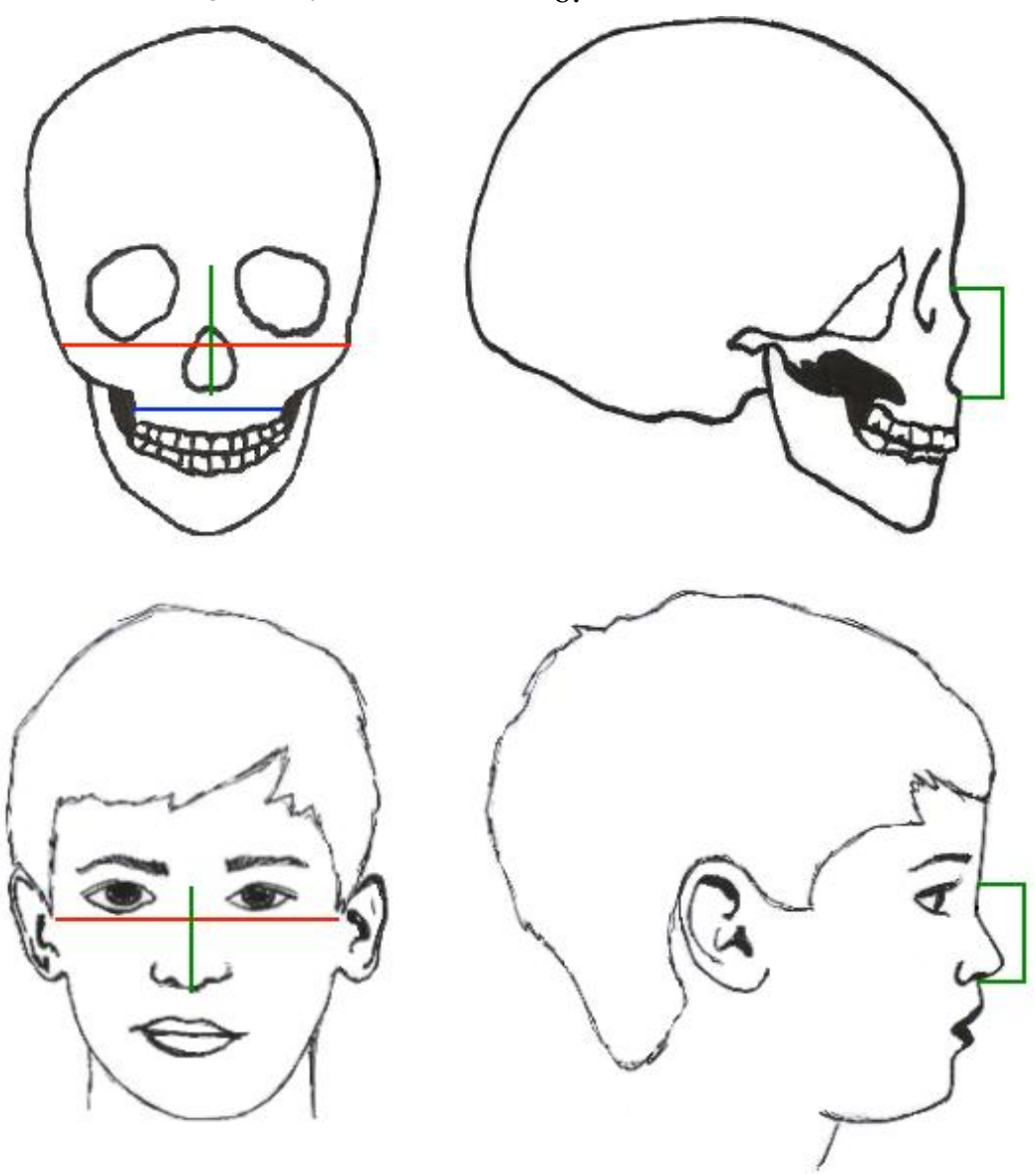

Figure6: Maxilla components (contains images from modified from [18, 41])

\begin{tabular}{|c|l|l|}
\hline \multicolumn{1}{|c|}{ Color Code } & \multicolumn{1}{|c|}{ Facial Component } & \multicolumn{1}{|c|}{ Section } \\
\hline & Bizygomatic Width & 3.5 .1 \\
\hline & Maxillary Width & 3.5 .1 \\
\hline & Vertical Growth & 3.5 .4 \\
\hline
\end{tabular}

\subsubsection{Maxillary Width}

Maxillary width growth, as measured from Maxilla to Maxilla $(M x-M x)$ (See Figure 3), is passive until around 7 years of age [16]. From ages 5 to 7 years, mean maxillary width is 52.7 $\mathrm{mm}$ and thus $91 \%$ of its size at 12 to 14 years, at which age it is $57.9 \mathrm{~mm}$ [9]. It has increased growth rapidity as early as 5 years until age 11 years, where growth plateaus $[17,20]$. Growth is basically complete at the eruption of the second molar, around age 12 [16]; at this age, males have $95 \%$ of their adult maxillary size and females have attained 98\% [20]. Maturation is at 15 years in males and 16 years in females [20].

The maxillary sinus height increases at a steady pace till the age of 12 years in both males and females irrespective of their race. However, it is unknown if the volume of the maxillary sinus occurs at a steady pace or if it takes place in bursts throughout adolescence [21]. See Figure 6. 


\subsubsection{Anteriorposterior Palate Growth}

Anteroposterior (front to back) growth has the same story as maxillary width and vault depth with early passive growth until around age 7 years, then an increase in growth until age 11 years [16-17]. Anteroposterior growth is complete by the time the individual hits puberty [16]. Interestingly, Brahim[16]states that during childhood the anterior portion of the maxilla is the "most traumatized region in the mouth" due to tooth loss.

\subsubsection{Palate and Cranial Vault Depth}

Vault depth is classified by passive growth early on, about 0 to 7 years, but can start to pick up speed around 5 years [16-17]. Growth then continues until around age 11 years where it plateaus until 15 years of age [16-17]. This growth greatly coincides with the deepening of the palate that occurs around the eruption of the second molars [22]. Additionally, Glowacki and Christoph [17] state that vault depth is one of the only parts of the maxilla to be sexually dimorphic.

\subsubsection{Maxillary Vertical Growth}

Vertical growth of the maxilla is measured from Nasion to Anterior Nasal Spine (N-ANS), Nasion to Stomion ( $N^{\prime}-S t o$ '), and or Nasion to Subnasale $\left(N^{\prime}-S n\right.$ ') (See Figure 3). Vertically, the maxilla is $67.3 \%$ of its adult size at age 1 year and reaches $82.2 \%$ by the age 5 years [23]. This portion of the maxilla grows on average around $24 \mathrm{~mm}$ between the ages of 1 to 18 years; $33 \%$ of this growth is complete at the age of 3 years and $54.9 \%$ of its growth is after age 5 years [7, 23]. Both skeletal and soft tissue show an average length of $46 \mathrm{~mm}$ at 7 years, $51 \mathrm{~mm}$ at 11 years, and $57 \mathrm{~mm}$ around 18 years; if one includes the upper lip and measures to the Stomion (Sto'), there is an additional $20 \mathrm{~mm}$ at the same ages (Moriera). Females reach maturity at age 12 years and males reach maturity at age 14 years [3, 23]. See Figure 6.

\subsection{Mandible}

The mandible widens transversely and is pushed anterio-inferiorly [18]. This simply means that as the mandible is gaining volume the ramus is flaring and elongating while the anterior portion of the mandible is jutting forward and morphing from a "round, smooth contour" to a pointed adult shape [24]. On average, the mandible is 60 to $70 \%$ of its adult size at age 1 year and 74 to $85 \%$ of its adult size at age 5 years [3]. Another way to look at these numbers is that the first five years encompass 24.0 to $25.2 \%$ of the overall mandibular growth [25]. The mandible hits its peak growth velocity right around puberty, which ranges between 13.6 and 14.5 years for males and between 10 and 12 years for females [26]. The mandible reaches maturity at age 16 years for males and age 14 years for females [3, 25]. For a visual of each mandibular component see, Figure 7.
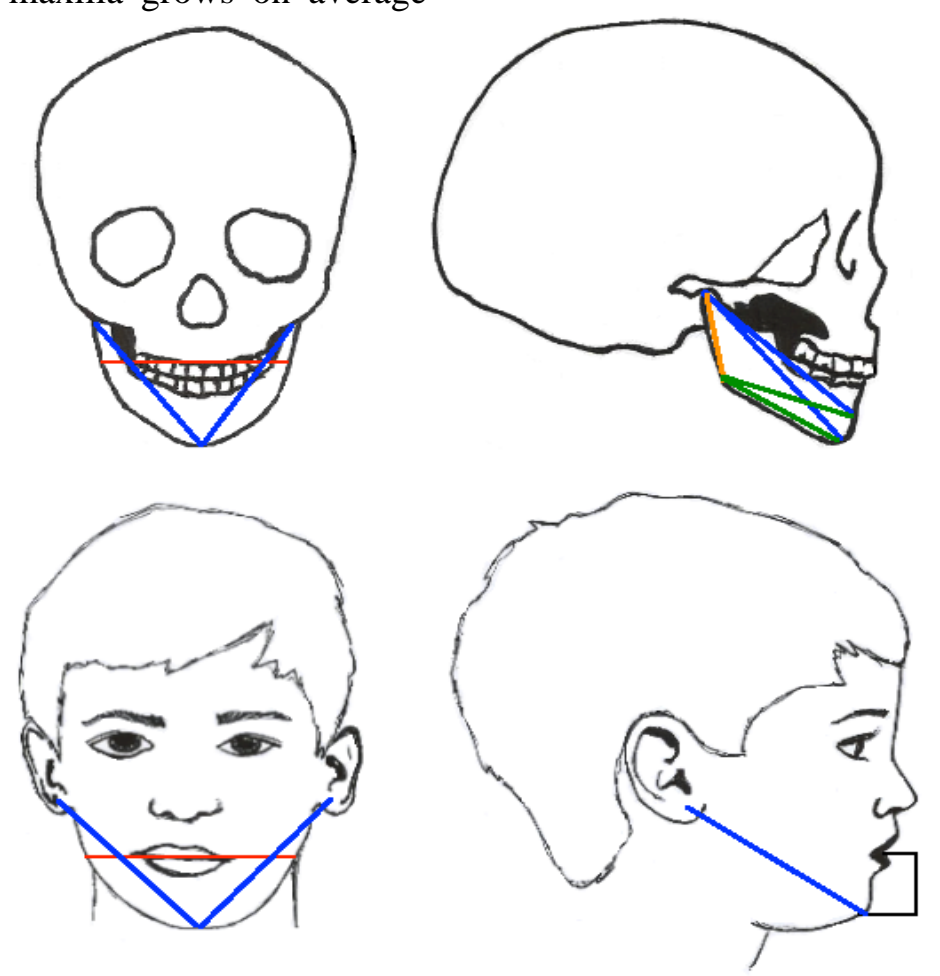

Figure7: Mandibular Components (contains images from [18, 41]) 


\begin{tabular}{|l|l|l|}
\hline Color Code & Facial Component & Section \\
\hline & Mandibular Width & 3.6 .1 \\
\hline & Mandibular Depth & 3.6 .2 \\
\hline & Mandibular Body Length & 3.6 .3 \\
\hline & Ramus Height & 3.6 .4 \\
\hline & Mandibular Body Height & 3.6 .5 \\
\hline
\end{tabular}

\subsubsection{Mandibular Width}

Mandibular width as measured from Gonion to Gonion (Go-Go; Go'-Go') (See Figure 3). Mandibular width is one of the earliest parts of the mandible to reach maturation due to how much of its growth is completed at the time of birth [23]. At birth, the bigonial width is already around $60 \%$ of its adult value [18]. The anterior portion of the mandible stabilizes at a faster rate and is established prior to the eruption of deciduous teeth; posterior growth, on the other hand, continues on at a rapid pace [16]. So much so that at 5 years of age it has reached a little over $92 \%$ of its average adult growth, growing $11 \mathrm{~mm}$ from ages 1 to 5 years [3,23]. Similarly, $\mathrm{Xu}$ et al. [9] have the distance between ages 5 to 7 years being $95 \%$ that of the distance measured at ages 12 to 14 years. Growth then continues with an average of 18 to $19 \mathrm{~mm}$ of expansion through 18 years, with measurements at age 10 years reaching $93.2 \mathrm{~mm}$ and $92.3 \mathrm{~mm}$ in males and females, respectively [20,23]. The age of maturation is shown to be 12 years for females and 13 years for males [3, 20, 23, 27]. See Figure 7.

\subsubsection{Mandibular Depth}

Mandibular depth is measured from Condylion to Gnathion ( $\mathrm{Co}-\mathrm{Gn})$, Condylion to the Symphysis Menti (Co-Sym.Me), and or Tragus to Gnathion $\left(T^{\prime}-G n^{\prime}\right)$ (See Figure 3). Mandibular depth has amazing growth patterns early in life. At age 4.4 years, $70 \%$ of growth is complete [8]. By the age of 5 years, the length ranges from $75 \%$ to as high as $85 \%$ of adult size [3, 23, 25].Glowacki and Christoph [17]state that "the most rapid increase in length was between 6 and 12 months of age" which highly correlates to the data found in studies by both Hutchinson et al. [24] and Liu et al. [25]; in these two studies, there is approximately $25 \mathrm{~mm}$ of growth in the first 3 years following birth. Farkas et al. [23]provide growth information excluding the crucial first year, indicating growth of $14.1 \mathrm{~mm}$ between 1 and 5 years and a $20.6 \mathrm{~mm}$ increase from 5 to 18 years. Even still, both of these growth patterns point out the general pattern of massive growth at the younger ages and then the subsequent deceleration of growth until puberty[16, 28].
Whereas, puberty may be expressed as having its onset and peak for females at age 9.54 years and 11.50 years, respectively. For males, onset of puberty occurs at age 11.56 years and has its subsequent peak at age 14.34 years [29]. Humphrey [8] has a more conservative, nonsexed average with $90 \%$ of growth achieved at age 13.4 years. Females attain adult maturation at 13 years of age and males at 15 years of age $[3,23]$. The average mandibular depth at 17 years of age is $126.9 \mathrm{~mm}$ for males and 117.3 $\mathrm{mm}$ for females [30]. See Figure 7.

\subsubsection{Mandibular Body Length}

Mandibular body length is measured from Gonion to Symphysis Menti (Go-Sym.Me), Gonion to Menton (Go-Me), and or Gonion to Gnathion (Go-Gn) (See Figure 3). Just as with other areas of the mandible, the body length has a decidedly quick growth pattern early on, with average gender percentages ranging around $77 \%$ of the adult size at the age of 5 years [25]. At around 5 years, growth in mandibular length is about $26 \%$ completed; this rate shows the length increasing 12 to $15 \mathrm{~mm}$ from birth to age 3 years $[24,25]$. Although no specific maturation ages were found in the studies analyzed, it is a resounding factor that male body length is larger than females and consistently lagging in maturity [25]. Also, between the ages of 5 and 7 years the mean length is $61.8 \mathrm{~mm}$, which is $90.2 \%$ of the size that it is at the ages of 12 to 14 years [9]. At ages 12 to 14 years, the mean of the mandibular length is around $68.5 \mathrm{~mm}$ [9]. Thus about $6.7 \mathrm{~mm}$ of growth occurs between those ages. The mandibular body is composed of two bone segments that eventually meet and fuse at the anterior portion of the mandible to create one continuous bone. When this fusing at the center occurs females are in the low $70 \mathrm{~mm}$ range with males being in the mid-70 to $80 \mathrm{~mm}$ range [25, 31]. See Figure 7.

\subsubsection{Ramus Height}

The Ramus height is considered from Articulare to Gonion $(A r-G o)$ and or Condylion to Gonion $(\mathrm{Ar}-\mathrm{Co})$ (See Figure 3). The ramus height follows the typical growth rate that has been established in the previous mandibular measurements with an incredibly swift velocity early on; however, the ramus is the slowest to 
mature out of the other areas $[8,25]$. The ramus starts out with only about $40 \%$ of its adult size at 0.4 years, but then increases around $31 \%$ in the next 5 years, establishing that by 5 years of age the ramus is approximately $70 \%$ of its adult size [25, 32]. Also, between 5 and 7 years, the mean length is $93.9 \mathrm{~mm}$, which is $89.5 \%$ of the mean length $(104.9 \mathrm{~mm})$ that it has reached between the ages of 12 and 14 years [9]. See Figure 7.

\subsubsection{Mandibular Body Height}

Mandibular body height was difficult to attain; the closest measurements that were found measured the "lower third face height." This is a soft tissue measurement and measured from Stomion to Gnathion (Sto'-Gn') and or Stomion to Menton (Sto'-Me') (See Figure 3), but will suffice until further mandibular statistics are collected. This measurement is $67 \%$ of its adult value at age 1 year, $87.8 \%$ at age 5 years, and attains its mature status in males at age 15 years and in females at age 12 years [23]. Another article stated that unsexed, skeletal anterior mandibular height was $70 \%$ complete by age 4.9 years and $90 \%$ by age 13.8 years [8]. It was reported that around two-thirds of lower third face height growth is complete between ages 1 and 5 years and specific growth spurts were noticeable between ages 1 and 2 years and ages 3 and 4 years [23]. Males grew a total of $9.7 \mathrm{~mm}$ during those two spurts, comprising $53.3 \%$ of their total growth between 1 and 18 years; whereas females grew $7.7 \mathrm{~mm}$ during the same peaks, comprising $55.8 \%$ of their growth from 1 to 18 years [23]. Around the age of 17 years, males measured at $52 \mathrm{~mm}$ and females at 46.9 $\mathrm{mm}$ [30]. See Figure 7.

\subsection{Facial Planes}

There is sequential growth in the face with cranial growth completing first, then facial widths (transverse plane), then facial depths (sagittal plane), and finally facial height (vertical plane) coming in last [20, 32]. These separate dimensions overlap, yet begin and end growth at different times [20].

\subsubsection{Cranial Width}

Cranial width, as measured from Euryion to Euryion $(E u-E u)$ (See Figure 3), is relatively large at birth with $65-70 \%$ of its adult value already complete[8, 18]. In order to keep up with the rapidity with which the brain is growing at this point in development, the cranium is speedily increasing with $84 \%$ of its adult value at year one and $90 \%$ complete by 1.9 years $[3,8]$. As seen by the next numbers, growth velocity decreases with $93 \%$ of adult value reached by 5 years of age and $95 \%$ complete at age $6[3,20]$. Maturation is age 14 in females and fluctuates between 15 and 17 years for males [3, 20]. For a visual component of cranial width, see Figure 5.

\subsubsection{Facial Height}

Facial height, often referred to as Anterior Facial Height (AFH), can be broken into two segments: upper facial height and lower facial height. Interestingly, lower facial height comprises 60 to $70 \%$ of total AFH growth [33]. However, rehashing the specifications of growth for both of those measurements is redundant since those numbers can be found under the maxillary vertical growth (upper face height; see section 3.3.2.5) and mandibular body height (lower face height; see section 3.3.1.5). In this section, only total anterior facial height will be discussed. Total anterior facial height is measured from Nasion to Menton $(\mathrm{N}-\mathrm{Me})$, Nasion to Gnathion $\left(N^{\prime}-G n^{\prime}\right)$, Nasion to Pogonion $\left(N^{\prime}-P g^{\prime}\right)$, and or Interpupillar Plane to Inferior Menton Margin (IPP'-Inf.Me') (See Figure 3. For a greater visual on $\mathrm{AFH}$, see Figure 5.

\subsubsection{Forehead}

The forehead measurement is from Trichion to Nasion $\left(T r^{\prime}-N^{\prime}\right)$ (See Figure 3). The forehead data in this assessment were ethnicity-specific data, encompassing a sample of Northern Sudanese children and adolscents. The forehead in males, between ages 4 and 5 years, were found to have attained $71 \%$ of their adult size, and were still only at $89 \%$ around ages 16 and 17 years [7]. Females, on the other hand, between the ages of 4 and 5 years, attained $80 \%$ of their adult size, and were $97 \%$ complete between the ages of 14 and 16 years [7]. Additionally, one non-ethnic specific detail is that the frontal bone on the whole is greater than $80 \%$ of its adult breadth at age 1 year [8]. Figure 5 shows the dimension of forehead height.

\subsection{Total Face}

The previous sections, from 3.4 to 3.8.3, catalogue the growth and development of the craniofacial complex as it pertains to the separate components. This section provides a general explanation of the concurrent growth of the facial aspects as a unified structure. See Figure 8 for a skeletal visual of the diachronic growth changes. See Appendix $\mathrm{C}$ for a cumulative layout of the growth measurements and percentages. 
At birth, craniofacial bones have attained approximately $45 \%$ of their total growth [18]. Compared to an adult skull, a newborn has a large cranial vault and enormous eye orbits in relation to the diminutive mandible and maxilla in concordance with the swift growth of the brain and eyes; in fact, most early growth is concomitant with the surrounding tissues in order to accommodate them [3-4, 32-33]. The cranial vault experiences its most rapid growth in the first year of life with a velocity plateau until area growth is complete between ages 5 and 7 years [3]. This coincides with a rapidity of head circumference enlargement, with $86 \%$ of growth complete at age 1 year and attaining $94 \%$ by around age 5 years [3].

The cranial volume is much larger in comparison to facial volume early on, but as age progresses the ratios of cranial volume to facial volume decrease (See Table 2). The face continues to expand during primary tooth eruption with an even greater increase in length during the mixed dentition stages, with the face lengthening twice comparatively to width between the ages of 4 and 13 years [4, 34].

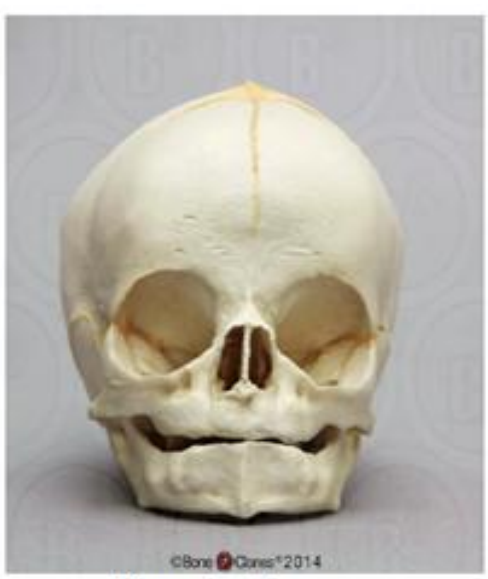

40 weeks- 0 years

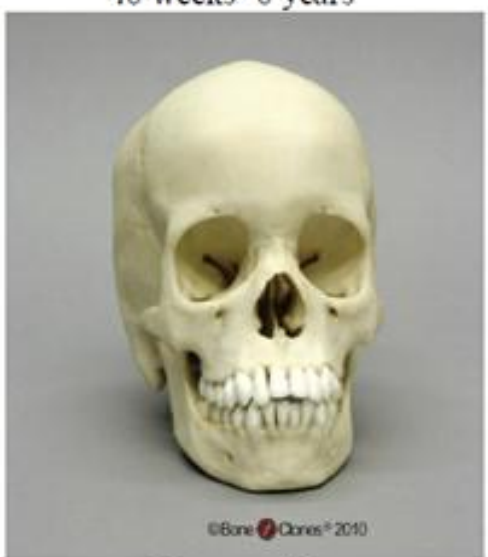

13 years old

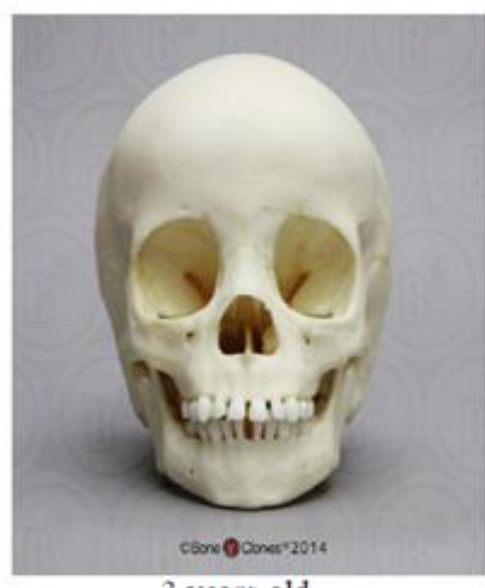

3 years old

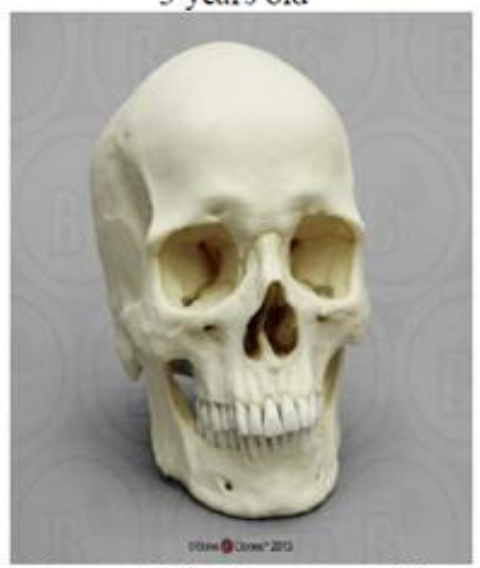

Human Male European Adult

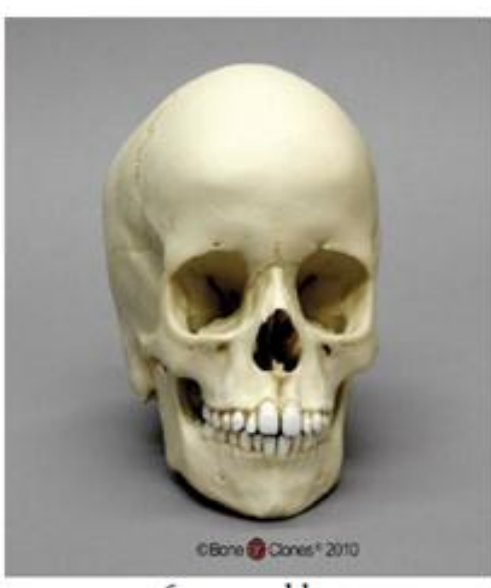

6 years old

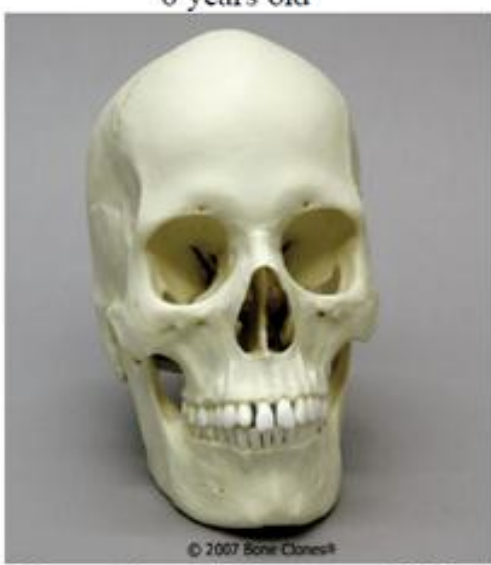

Human Female European Adult

Figure8: Diachronic Craniofacial Appearance (Images from [42])

Table2: Cranial Volume to Facial Volume Ratio (adapted from [4])

\begin{tabular}{|l|l|}
\hline \multicolumn{1}{|c|}{ Age } & \multicolumn{1}{c|}{ Ratio } \\
\hline Birth (0 years) & $8: 1$ \\
\hline 2 years & $5: 1$ \\
\hline 6 years & $3: 1$ \\
\hline 12 years & $2.5: 1$ \\
\hline 18 years & $2: 1$ \\
\hline
\end{tabular}

As stated previously, the mandible and maxilla have both reached approximately $85 \%$ of their adult size at age 5 years. To be sure, most rapid growth is complete by age 7 years with facial development largely complete ( 82 to $92 \%$ ) by age 5 years $[10,23,35]$. Concordantly, at age 7 years, the craniofacial bones have reached around $70 \%$ of their adult size; at this age, ideally, the soft tissue facial profile measured from Glabella to Subnasale ( $G^{\prime}-S n$ '; midway between the eyebrows to below the nose) is equal in length to Subnasale to Menton ( $S n^{\prime}$ $M e$ '; below the nose to the chin) (See Figure 3) [18]. Specific sexual dimorphism (shape 
differences in females and males) begins to appear around age 9 years [27]. Passive growth is from around age 7 years until puberty [35]. Puberty generally occurs around age 10 to 12 years in females, and age 12 to 14 years in males; this time period is marked by an increased growth velocity that peaks about two years after onset [18]. For growth spurts, males are found to lag behind females by one to three years yet be larger in their craniofacial dimensions, especially after puberty [20, 27]. Although technically craniofacial growth is continuous, after 20 years of age, the rate and extent of growth appears insignificant and is likely tied to basic bone remodeling that throughout life [27, 33].

Children's faces do not merely grow in volume to attain adult morphology and size; they are more than a small-scale adult, even though at age 3 years there is already a significant correlation to their adult morphology [17, 35]. The brain case is rapidly expanded after birth followed by the mid-facial projection and elongation [18]. Children's faces flatten, deepen, widen, and lengthen to achieve the adult appearance $[11,18,32,35-36]$. The adult length is about twice the length of the child's face and the cranial volume to facial volume ratios can be seen in Table 2 as previously mentioned [18]. The total transverse growth reaches maturity around 15 years in females and 17 years in males; total vertical growth continues beyond 15 years of age in both sexes; mid-facial projection ( $T$ '-Sto'; see Figure 3 ) reaches maturity at 14 years in males and 13 years in females; and final size maturity is attained between 13 and 15 years in females and 17 and 25 years in males [3, 20, 27-28].

The maxillary prominence angle decreases progressively throughout childhood, and increases after adolescence. It was noted that the maxillary prominence angle values were larger in male subjects in comparison to female subjects [37]. In females between the ages of 10 and 17 years the mentolabial angle decreased progressively with age. According to the crosssectional study Sforza et al. [37]conducted on the soft tissue profile of native Northern Sudanese subjects aged 4 to 30 years, female subjects overall had a significantly more obtuse mentolabial angle than males. The maxillary prominence angle (sl-n-sn) decreased during childhood, as noted before, and the lowest angle value was for individuals aged 12 to 15 years.
EL-Batran et al. [38] noted morphological sex differences in that males have larger linear and angular measurements than females, most evident in the lower facial region. The pattern of the cranial base is related to variation in maxilla-facial form, with correlation between parts of the basicranium and the maxillo-facial complex. This relationship is more prominently seen in males and reflects the "differential growth pattern of the face which is time and sex linked". Cranial base angle is greater than 8 degrees in males, and 7 degrees in females. The more obtuse a cranial base angle, the greater association with a more divergent facial type. The intersphenoidal synchondrosis ossifies immediately before birth and the ethmoidal synchondrosis ossifies 7 years after birth, with the growth of the central area of the cranium complete in the early stages of life. The growth and development of the cranium is a result of the anterior growth of the frontal bone. The growth and development of the posterior cranial base is due to the activity of the sphenooccipital synchondrosis.

Mellion et al. [29]examined the relationship in height, facial size, and mandibular length at the onset of pubertal growth spurts in females and males at 9.3, 9.8, and 9.5 years of age. Facial size pubertal growth spurt onset in males begins at a mean age of 11.95 years, with the peak being reached at a mean age of 14.35 years. Female facial size pubertal growth spurt onset was recorded at age 9.77 years, with peak being notedat a mean age of 11.5 years. Mandibular length pubertal growth spurt onset in malesoccurred at a mean age of 11.86 years withpeak being at a mean age of 14.34 years; in females this beganat a mean age of 9.54 years and peaked at a mean age of 11.50 years.

Using 3D facial models, the facial growth of individuals aged 12 to 15 years was tracked by [39]. It was determined that males undergo more facial changes than females, especially in the eyebrow ridges, nose and chin regions. In 23 males examined they obeservedthe occurrence of anterior growth of the brow ridges, an increase in nose prominence and an enlargement of the downward projection of the chin as ageincreased. It is thought that the nose becomes more prominent as the increased prominence in the lower and upper lips begins to shift downward. A flattening of the cheeks and deepening of the orbital region in relation to more prominent brow ridges is visible throughout the different ages in the 12 to 15 
year age range (i.e., at 12, 13,14, and15 years of age). In females, an overall elongation and widening of the face, a more deeply positioned orbital area in relation to the eyes, and a regression of soft tissues between the nasolabial creases became more prominent with age. It is also clear that a more prominent nose is seen in the older age in this range (i.e., age 15 years).

Gibelli et al.[40]studied the relationship between profile reconstruction and midfacial soft-tissue thickness in 222 children and young adults. Males exhibited thicker soft tissue than females ofthe same age, especially after the adolescent growth spurt. Of 14 midfacial landmarks, 9 showed significant age-related increases of soft tissue development. The subnasal, superior labial sulcus, labralesuperius, labraleinferius, stomion, pogonion, and gnathion, all changedsignificantly with age. The middle and lower third of the facial region is where all the aforementioned landmarks are located, and where age- and sex-related variation occurs most prominently. It should also be noted that Gibelli et al.[40]suggestthat ancestry (i.e., population of origin, ethnicity) plays a large role in soft tissue variation.

\section{Discussion AND CONCluSions}

This research is an explication of craniofacial growth and development as singular components, wherein singular components of the face and their changes are explained, ending with a summary of how these individualized parts develop in tandem with one another. Darwis et al. [27] suggest that simply uniting the distinct sections to create a picture of the whole falls short of the realistic growth and development rate and pattern. However, by further understanding the growth velocities and peak growth spurts of singular aspects, one can better understand how each of the moving parts creates the greater whole. This study synthesized data relating to the key components of the developing facial complex into a fluid description in order to display the full pattern of craniofacial growth and development from birth through maturation at 18 years.

Growth and development of sub-adults follows a general pattern; however, determining specific individual growth patterns is complicated because children's faces grow at different velocities and may mature at a pace that is either delayed or advanced compared to other children of the same age [26]. In addition, any time prediction comes into play there is an artistic element involved. Nevertheless, by tracking which parts of the face change at which point in time, it becomes easier to age-progress (or regress) the minute changes occurring in the growing and developing craniofacial complex.

The major growth pattern presents an infant with a very large cranial volume compared to the diminutive facial complex. The facial complex proceeds to grow swiftly throughout the first few years of life, elongating in the lower and mid-facial aspects. The velocities then decline and the total face proceeds to gain volume, length, and width until it attains its adult dimensions.

By determining facial maturational changes, researchers can develop technologies in concordance with age-progression, ageregression, and identification for use in the Identity Sciences. Age-progression has been explored in order to project known images of missing children to reflect their current age. For example, if seven years have elapsed since the disappearance of a 3 year old child, looking for a 3 year old is no longer pertinent; a relevant picture would show the child to be of 10 years of age.

The concept of facial identification was originally promulgated on the national circuit with motivations arising from Homeland Security. This technology has and is migrating into daily use for individual access on personal devices, for example, vehicles, cellular devices, computers, and televisions. Looking forward, identification technologies are focusing more on facial analytics - the ability to derive useful information from the face-for research encompassing areas from medical assessments in the health insurance sector to consumer purchasing patterns for aid in new marketing techniques. These innovative ideas are adultfocused and it remains to be seen how juvenile faces will be integrated into such arenas. In summary, the research provided within offers a synchronic and diachronic explanation of subadult craniofacial morphological growth and development relevant for advancing technologies within the Identity Sciences.

\section{REFERENCES}

[1] Higgins J.P.T, Green S. (Eds) Cochrane Handbook for Systematic Reviews of Interventions. Version 5.1.0., 2011, The Cochrane Collaboration. www.cochranehandbook.org

[2] Berger A.J. Growth and development of the orbit. Oral Maxillofacial Surg.Clin. N. Am., 24, (2012). 545-555. 
[3] Costello B.J., Rivera R.D., Shand J., Mooney M. Growth and development considerations for craniomaxillofacial surgery. Oral Maxillofacial Surg.Clin. N. Am. 24, (2012), 377-396.

[4] Cohen M.M. Jr. Chapter 1: The new perspectives on the face, in JC Posnick (Ed) Orthognathic Surgery: Principles \& Practice, St. Louis, MO: Elsevier Saunders, 2014, Pp 1-17.

[5] Sforza C., Grandi G., Catti F., Tommasi D.G., Ugolini A., Ferrario V.F. Age- and sex-related changes in the soft tissues of the orbital region. Forensic Sci. Int. 185, (2009), 115.e1-115.e8.

[6] Sforza C., Dolci C., Gibelli D.M., Codari M., Pucciarelli V., Ferrario V.F., Elamin F. Agerelated and sex-related changes in the normal soft tissue profile of native Northern Sudanese subjects: A cross-sectional study. J. Oral Maxillofac. Surg. 54, (2016), 192-197.2013

[7] Sforza C., Dolci C., Tommasi, D.G., Pisoni L., De Menezes M., Elamin F., Three-dimensional facial distances of Northern Sudanese persons from childhood to young adulthood, J. Craniomaxillofac. Surg. 42, (2014), e318-e326.

[8] Humphrey L.T., Growth patterns in the modern human skeleton. Am. J. Phys.Anthropol. 105, (1998), 57-72.

[9] Xu Y., Yang C., SchreuderW.H., ShiJ., ShiB., ZhengQ., WangY., Cephalometric analysis of craniofacial morphology and growth in unrepaired isolated cleft palate patients, J. Craniomaxillofac.Surg, (2014),1-8.

[10] Yang G., Wang J., Chang Q., Wang Z., Geng Y., Li D. Digital evaluation of orbital development in Chinese children with congenital micropthalmia. Am. J.Opthalmol. 154, (2012), 601-609.

[11] Boyette J.R. Facial fractures in children. Otolaryngol.Clin. N. Am. 47, (2014), 747-761.

[12] Park, S.W., ChoiJ., ParkH.O., LimY.S., LeeK.D., KimN.G., KimJ.S., Are gender differences in external noses caused by differences in nasal septal growth? J CraniomaxillofacSurg, (2014), 1-8.

[13] Sforza C., Grandi G., De Menezes M., Tartaglia G.M. Age- and sex-related changes in the normal human external nose. For. Sci. Int. 204, (2010), 205.e1-205.e9.

[14]ChenF., ChenY., YuY., QiangY., LiuM., FultonD., ChenT. Age and sex related measurement of craniofacial soft tissue thickness and nasal profile in the Chinese Population, Forensic Sci. Int. 212, (2011), 272.e1-272.e6.

[15] Sun M., Yoshiaki O., Yuzo T. Prediction of the upper airway growth in normal children. Pediatr. Dent. J. 22, (2012), 35-42.

[16] BrahimJ.S. Dental Implants in Children. Oral Maxilllofacial Surg.Clin. N. Am. 17, (2005), 375-381.
[17] GlowackiJ., ChristophK. Gender differences in the growing, abnormal, and aging jaw, Dent.Clin. N. Am. 57, (2013), 263-280.

[18] Ferguson D.J., Dentistry for the Child and Adolescent ( $9^{\text {th }}$ Ed.) Chapter 25: Growth of the Face and Dental Arches, C.V. Mosby Co., 2010.

[19] AngelieriF., CevidanesL.H.S., FranchiL., GonçalvesJ.R., BenavidesE., McNamara Jr.J.A. Midpalatal suture maturation: Classification method for individual assessment before rapid maxillary expansion, Am. J.Orthod. Dentofacial. Orthop. 144, (2013), 759-769.

[20] Nanda R., Snodell S.F., Bollu P. Transverse growth of the maxilla and mandible. Semin. Orthod. 18, (2012), 100-117.

[21] Smith S.L., Buschang P.H., Dechow P.C. Growth of the maxillary sinus in children and adolescents: A longitudinal study. HOMO 68, (2016), 51-62.

[22] KatoM., KajimotoY., MatsuoH., IkemotoH., KunimotoA., KatoS., DaitoM. Three dimensional measurements of the palate using the semiconductor laser 3. Changes in the palate section areas, palate projection areas and palate volumes in the early permanent dentition according to age, Pediatr. Dent. J. 20 (2), (2010), 165-170.

[23] FarkasL.G., PosnickJ.C., HreczkoT.M. Growth patterns of the face: a morphometric study, Cleft Palate Craniofac. J. 29 (4), (1992), 308315.

[24] HutchinsonE.F., L'Abbé,E.N.,OettléA.C.An assessment of early mandibular growth, Forensic Sci. Int. 217, (2012), 233.e1-233.e6.

[25] LiuY.P., BehrentsR.G., BuschangP.H. Mandibular growth, remodeling, and maturation during infancy and early childhood, Angle Orthod. 80, (2010), 97-105.

[26] SuriS., PrasadC., TompsonB., LouW. Longitudinal comparison of skeletal age determined by the Greulich and Pyle method and chronologic age in normally growing children, and clinical interpretations for orthodontics, Am. J.Orthod. Dentofacial Orthop. 143, (2013), 50-60.

[27] DarwisW.E., MesserL.B., ThomasC.D.L. Assessing growth and development of the facial profile, Pediatr Dent 25, (2003), 103-108.

[28] ChvatalB.A., BehrentsR.G., CeenR.F., Buschang, P.H. Development and testing of multilevel models for longitudinal craniofacial growth prediction. Am. J.Orthod. Dentofacial Orthop. 128, (2005), 45-56.

[29] Mellion Z.J., Behrents R.G., Johnston L.E. Jr. The pattern of facial skeletal growth and its relationship to various common indexes of maturation. Am. J.Orthod. Dentofacial Orthop. 143, (2013), 845-854. 
[30] PecoraN.G., BaccettiT., McNamara Jr.J.A. The aging craniofacial complex: A longitudinal cephalometric study from late adolescence to late adulthood, Am. J.Orthod. Dentofacial Orthop. 134, (2008), 496-505.

[31] SubramaniamP., NaiduP. Mandibular dimensional changes and skeletal maturity, ContempClin Dent 1 (4), (2010), 218-222.

[32] Buschang P., Hinton R. A gradient of potential for modifying craniofacial growth. Semin. Orthod. 11, (2005), 219-226.

[33] FudalejP., KokichV.G., LerouxB. Determining the cessation of vertical growth of the craniofacial structures to facilitate placement of single-tooth implants. Am. J.Orthod.. Dentofacial Orthop. 131, (2007), s59-s67.

[34] CasteloP.M., PereiraL.J., BonjardimL.R., GaviãoM.B.D.Changes in bite force, masticatory muscle thickness, and facial morphology between primary and mixed dentition in preschool children with normal occlusion, Ann. Anat. 192, (2010), 23-26.

[35] TaylorK.T. Forensic art and illustration, CRC Press LLC, 2001.

[36] MurakamiD., InadaE., SaitohI., TakemotoY., MorizonoK., KubotaN., IwasakiT., OkuT., YamasakiY. Morphological differences of facial soft tissue contours from child to adult of Japanese males: A three-dimensional cross-

\section{Appendix A: Search Iterations}

\begin{tabular}{|c|c|c|c|c|}
\hline Search Iterations & Yrs Searched & \# of Hits & $\begin{array}{c}\text { Estimated \# } \\
\text { Searched }\end{array}$ & \# Pulled \\
\hline Human Craniofacial Growth & 2004-present & $\begin{array}{l}11,672 \\
11,691 \\
11,725\end{array}$ & \begin{tabular}{|l} 
Example-1 \\
75 \\
150
\end{tabular} & $\begin{array}{l}1 \\
14 \\
4 \\
(19)\end{array}$ \\
\hline Human Oral and Maxillofacial Growth; Children & 2004-present & 2,270 & 100 & 2 \\
\hline Human Craniofacial Development & 2004-present & 13,719 & 100 & 1 \\
\hline Craniofacial Maturation Stages & 2004-present & 3,161 & 50 & 0 \\
\hline Human Craniofacial Stages; Birth to Maturation & 2004-present & 1,506 & 100 & 1 \\
\hline Sub-Adult Facial Development & 2009-present & 5,480 & 150 & 11 \\
\hline Face Changes; Children & 2009-present & 86,725 & 200 & 8 \\
\hline Human Facial Maturation & 2009-present & 5,275 & 125 & 9 \\
\hline Human Face Growth & 2009-present & 127,790 & 125 & 9 \\
\hline Childhood Facial Development & 2009-present & 11,300 & 75 & 1 \\
\hline Infant Face Growth & 2009-present & 14,933 & 75 & 1 \\
\hline Infant Face Development & 2009-present & 25,648 & 75 & 0 \\
\hline Infant Face Maturation & 2009-present & 5,266 & 75 & 0 \\
\hline Child Face Growth & 2009-present & 41,781 & 125 & 2 \\
\hline Child Face Development & 2009-present & 84,609 & 75 & 0 \\
\hline Child Face Maturation & 2009-present & 9,794 & 100 & 1 \\
\hline Infant Child Face Growth & 2009-present & 12,101 & 100 & 0 \\
\hline Orbital Growth & 2009-present & 31,038 & 100 & 5 \\
\hline Orbital Maturation & 2009-present & 2,967 & 75 & 0 \\
\hline Human Nasal Arch Growth & 2009-present & 7,482 & 100 & 2 \\
\hline Facial Muscle Anchors on Bone & 2009-present & 599 & 50 & 0 \\
\hline Craniofacial Muscle and Bone Correlation & 2009-present & 1,686 & 75 & 0 \\
\hline Facial Bone Maturation & 2009-present & 3,137 & 75 & 0 \\
\hline Face Growth Over Time & 2009-present & 209,497 & 75 & 1 \\
\hline
\end{tabular}

sectional study, Arch. Oral. Biol. 59, (2014), 1391-1399.

[37] Sforza C., Dolci C., Gibelli D.M., Codari M., Pucciarelli V., Ferrario V.F., Elamin F. Agerelated and sex-related changes in the normal soft tissue profile of Native Sudanese subjects: a cross-sectional study, Oral Maxiollofac. Surg. 54, (2016), 192-197.

[38] El-Batran M., Soliman N., El-Wakil K.H. The relationship between cranial base and maxillafacial morphology in Egyptian children. HOMO 59, (2008), 287-300.

[39] Koudelova J., Dupej J., Bruzek J., Sedlak P., Veleminska J. Modeling of facial growth in Czech children based on longitudinal data: Age progression from 12 to 15 years using 3D surface models. Forensic Sci. Int. 248, (2015), 33-40.

[40] Gibelli D., Collini F., Porta D., Zago M., Dolci C., Cattaneo C., Sforza C. Variations of midfacial soft-tissue thickness in subjects aged between 6 and 18 years for the reconstruction of the profile: A study on an Italian sample. Leg. Med. (Tokyo) 22, (2016), 68-74.

[41] White T.D., Black M.T., and Folkens P.A., Human Osteology ( $3^{\text {rd }}$ Ed.), Elsevier INC, 2012.

[42] Bone Clones, Inc. Osteological Reproductions. Copyright (C) 1995-2015 Bone Clones®http:// www. boneclones.com/ 


\begin{tabular}{|c|c|c|c|c|}
\hline Human Mandible Development & 2009-present & 7,372 & 75 & 1 \\
\hline Human Maxilla Development & 2009-present & 3,717 & 75 & 1 \\
\hline Human Skull Changes & 2009-present & 20,798 & 75 & 1 \\
\hline Human Skull Growth & 2009-present & 10,234 & 75 & 0 \\
\hline Facial Skeletal Stages & 2009-present & 6,104 & 100 & 1 \\
\hline Soft Tissue Facial Growth & 2009-present & 9,987 & 75 & 1 \\
\hline Maxillofacial Soft Tissue Development & 2009-present & 6,086 & 75 & 0 \\
\hline Children Facial Muscle Development & 2009-present & 9,354 & 75 & 0 \\
\hline Pediatric Craniofacial Growth & 2009-present & 2,725 & 75 & 1 \\
\hline Facial Muscle Growth & 2009-present & 10,733 & 75 & 0 \\
\hline Search Iterations & Yrs Searched & \# of Hits & $\begin{array}{c}\text { Estimated \# } \\
\text { Searched }\end{array}$ & \# Pulled \\
\hline $\begin{array}{l}\text { Overlay of Muscle, Bone, and Soft Tissue } \\
\text { Development }\end{array}$ & 2009-present & 732 & 75 & 0 \\
\hline Post-Natal Craniofacial Growth and Development & 2009-present & 1,133 & 75 & 1 \\
\hline Orofacial Development & 2009-present & 4,667 & 75 & 0 \\
\hline Growth and Development of Craniofacial Complex & 2009-present & 5,448 & 100 & 0 \\
\hline Nasomaxillary Complex Development & 2009-present & 148 & 148 & 0 \\
\hline Sub-Adult Mandible & 2009-present & 1,669 & 25 & 0 \\
\hline Sub-Adult Human Mandible Growth & 2009-present & 742 & 100 & 0 \\
\hline Human Child Mandibular Growth & 2009-present & 2,592 & 100 & 1 \\
\hline Sub-Adult Nasal Bone Growth & $\begin{array}{l}\text { 2009-present } \\
\text { 2000-present }\end{array}$ & $\begin{array}{l}2,522 \\
4,219\end{array}$ & $\begin{array}{l}100 \\
100\end{array}$ & $\begin{array}{l}0 \\
0\end{array}$ \\
\hline Human Nasal Growth & 2000-present & 39,315 & 50 & 0 \\
\hline Human Nasal Bone Development & 2000-present & 25,015 & 100 & 0 \\
\hline Search Iterations & Yrs Searched & \# of Hits & $\begin{array}{l}\text { Estimated } \\
\text { Searched }\end{array}$ & \# Pulled \\
\hline Facial Growth and Children & 2007-present & 18,669 & 75 & 1 \\
\hline Facial Maturation and Children & 2007-present & 5,121 & 50 & 4 \\
\hline Orbital Growth and Children & 2007-present & 12,617 & 50 & 1 \\
\hline Nasal Growth and Children & 2007-present & 14,622 & 50 & 2 \\
\hline Nose Growth and Children & 2007-present & 31,495 & 50 & 3 \\
\hline Facial Appearance and Sub Adults & 2007-present & 313 & 25 & 3 \\
\hline Maxilla and Jaw Development & 2007-present & 11,632 & 50 & 1 \\
\hline Maxillary Growth & 2007-present & 20,719 & 100 & 3 \\
\hline Maxillary Growth and Children & 2007-present & 14,573 & 50 & 2 \\
\hline Faces and Soft Tissue & 2007-present & 130,281 & 100 & 1 \\
\hline Children and Fat Changes & 2007-present & 49,782 & 50 & 1 \\
\hline Total: & & & 4,248 & $\begin{array}{l}81 \\
103\end{array}$ \\
\hline
\end{tabular}

Appendix B: References Broken Down According to Craniofacial Component

\begin{tabular}{|c|c|c|c|}
\hline Mandible & Maxilla & Orbits & Nasal \\
\hline Brahim, 2005 & Angelieri et al., 2013 & Berger, 2012 & Chen et al., 2011 \\
\hline Buschang and Hinton, 2005 & Brahim, 2005 & Boyette, 2014 & Park et al., 2014 \\
\hline Chvatal et al., 2005 & Castelo et al., 2010 & Cohen, 2014 & Sforza et al., 2010 \\
\hline Costello et al., 2012 & Costello et al., 2012 & Costello et al., 2012 & Sun et al., 2012 \\
\hline Darwis et al., 2003 & Darwis et al., 2003 & Humphrey, 1998 & \\
\hline Farkas et al. 1992 & Farkas et al. 1992 & Sforza et al., 2009 & \\
\hline Ferguson, 2010 & Ferguson, 2010 & Sforza et al., 2013 & \\
\hline Glowackiand Christoph, 2013 & Glowacki and & Sforza et al., 2014 & \\
\hline Humphrey, 1998 & 2013 & Xu et al., 2014 & \\
\hline Hutchinson et al., 2012 & Kato et al., 2010 & Yang et al., 2012 & \\
\hline Mellion et al., 2013 & Nanda et al., 2012 & & \\
\hline Nanda et al., 2012 & Moreira et al., 2014 & & \\
\hline Pecora et al., 2008 & Sforza et al., 2014 & & \\
\hline Liu et al., 2010 & Xu et al., 2014 & & \\
\hline Subramaniam and & Hohoff et al., 2006 & & \\
\hline 2010 & Smith et al., 2017 & & \\
\hline Suri et al., 2013 & & & \\
\hline Xu et al., 2014 & & & \\
\hline
\end{tabular}




\begin{tabular}{|c|c|c|c|}
\hline Cranial Width & Face Height & Forehead & Total Face \\
\hline \begin{tabular}{|l} 
Costello et al., 2012 \\
Ferguson, 2010 \\
Humphrey, 1998 \\
Nanda et al., 2012
\end{tabular} & $\begin{array}{l}\text { Darwis et al., } 2003 \\
\text { Farkas et al. } 1992 \\
\text { Ferguson, 2010 } \\
\text { Fudalej et al., } 2007 \\
\text { Moreira et al., } 2014 \\
\text { Sforza et al., } 2014 \text { Vieira et } \\
\text { al., } 2011 \\
\text { Aarts et al., } 2015\end{array}$ & $\begin{array}{l}\text { Humphrey, } 1998 \\
\text { Sforza et al., } 2014\end{array}$ & \begin{tabular}{|l|} 
Boyette, 2014 \\
Buschang and Hinton, 2005 \\
Castelo et al., 2010 Chvatal et \\
al., 2005 \\
Cohen, 2014 \\
Costello et al., 2012 \\
Darwis et al., 2003 \\
Farkas et al. 1992 \\
Ferguson, 2010 \\
Fudalej et al., 2007 \\
Glowacki and Christoph, \\
2013 \\
Murakami et al., 2014 \\
Nanda et al., 2012 \\
Taylor, 2011 \\
Yang et al., 2012 \\
EL-Batran et al., 2008 \\
Caplova et al., 2017 \\
Mellion et al., 2013 \\
Koudelova et al., 2014 \\
Gibelli et al., 2016
\end{tabular} \\
\hline
\end{tabular}

\section{Appendix C: Cumulative Craniofacial Growth Chart}

Chart Terminology: (a) Age is depicted in years. (b) Age 0 is herein defined as "at birth." (c) Any parenthetical number is an indication of a specific age that is more precise than the chart's numbers in the left margin. (d)All percentages found in this graph are the percentages of the adult size already achieved at that age, with "adult size" defined as age 18. (e) Each of the measurements and percentages are further explained in the Results section.

\begin{tabular}{|c|c|c|c|c|c|c|c|c|}
\hline Age & Sex & Mandible & Maxilla & Orbits & Cranial Width & AFH & Forehead & Total Face \\
\hline \multirow[t]{2}{*}{0} & $\mathbf{M}$ & Width: $60 \%$ & Bizygomatic: & (.9) Total & \multirow[t]{2}{*}{$65-70 \%$} & \multirow[t]{2}{*}{$40 \%$} & & \multirow{2}{*}{$\begin{array}{l}\text { Craniofacia } \\
1 \quad \text { Bones: } \\
45 \%\end{array}$} \\
\hline & $\mathbf{F}$ & $\begin{array}{l}\text { (.4) Ramus height is } \\
40 \%\end{array}$ & $500 \%$ & $\begin{array}{l}\text { Total } \\
170 \%\end{array}$ & & & & \\
\hline \multirow[t]{2}{*}{$\mathbf{1}$} & $\mathbf{M}$ & Average $\quad$ Total & \multirow{2}{*}{$\begin{array}{l}\text { Vertical } \\
\text { Growth: } 67.3 \%\end{array}$} & & \multirow{2}{*}{$\begin{array}{l}84 \% \\
(1.9) 90 \%\end{array}$} & mid-50\% & Frontal & \multirow{2}{*}{$\begin{array}{l}\text { Head } \\
\text { Circumfere } \\
\text { nce: } 86 \%\end{array}$} \\
\hline & $\mathbf{F}$ & $\begin{array}{l}\text { Growth: } 60-70 \% \\
\text { Body Height: } 67 \%\end{array}$ & & & & $\begin{array}{l}\text { to high- } \\
60 \%\end{array}$ & $\begin{array}{l}\text { Bone: } \\
80 \%\end{array}$ & \\
\hline \multirow[t]{2}{*}{2} & $\mathbf{M}$ & & & & & & & \\
\hline & $\mathbf{F}$ & & & & & & & \\
\hline \multirow[t]{2}{*}{3} & $\mathbf{M}$ & & & \multirow{2}{*}{$\begin{array}{l}\text { Volume: } \\
69 \%\end{array}$} & & & & \\
\hline & $\mathbf{F}$ & & & & & & & \\
\hline \multirow[t]{2}{*}{4} & $\mathbf{M}$ & \multirow[t]{2}{*}{ (4.4) Depth: 70\% } & & \multirow{2}{*}{$\begin{array}{l}\text { (4.5) Height } \\
78 \% \\
\text { Intercanthal } \\
\text { width, } \\
\text { females: } 98 \%\end{array}$} & & & $(4-5) 71 \%$ & \\
\hline & $\mathbf{F}$ & & & & & & $(4-5) 80 \%$ & \\
\hline \multirow[t]{2}{*}{5} & $\mathbf{M}$ & $\begin{array}{l}\text { Width: } 92 \% \\
\text { Depth: } 75-85 \% \\
\text { Body Length: } 77 \% \\
\text { Ramus Height: } 70 \% \\
\text { Body Height: } 87.8 \% \\
\text { Average }\end{array}$ & & \multirow[t]{2}{*}{$\begin{array}{l}\text { Average } \\
\text { Intercanthal } \\
\text { lwidth: } 93 \% \\
\text { Volume: } \\
90 \%\end{array}$} & \multirow[t]{2}{*}{$93 \%$} & \multirow[t]{2}{*}{$80 \%$} & & \multirow[t]{2}{*}{$\begin{array}{l}\text { Head } \\
\text { Circumfere } \\
\text { nce: } 94 \% \\
\text { Facial } \\
\text { Developme } \\
\text { nt: } 82-92 \%\end{array}$} \\
\hline & $\mathbf{F}$ & Growth: $74-85 \%$ & & & & & & \\
\hline Age & Sex & Mandible & Maxilla & Orbits & $\begin{array}{l}\text { Cranial } \\
\text { Width }\end{array}$ & AFH & Forehead & Total Face \\
\hline \multirow[t]{2}{*}{6} & $\mathbf{M}$ & & \multirow{2}{*}{\begin{tabular}{|l|} 
Bizygomatic: \\
$84.5 \%$ \\
Intermolar width \\
has reached adult \\
size.
\end{tabular}} & \multirow{2}{*}{$\begin{array}{|ll|}6.5) & \text { Height } \\
88 \% & \\
& \\
\end{array}$} & \multirow[t]{2}{*}{$95 \%$} & & & \\
\hline & $\mathbf{F}$ & & & & & & & \\
\hline \multirow[t]{2}{*}{7} & $\mathbf{M}$ & & \multirow[t]{2}{*}{ Vertical: $46 \mathrm{~mm}$} & \multirow{2}{*}{$\begin{array}{l}(7.5) \text { Orbital } \\
\text { width } 90 \%\end{array}$} & & $(7-10)$ & & \multirow{2}{*}{$\begin{array}{l}\text { Craniofacia } \\
1 \quad \text { Bone: }\end{array}$} \\
\hline & $\mathbf{F}$ & & & & & $106.0 \pm$ & & \\
\hline
\end{tabular}




\begin{tabular}{|c|c|c|c|c|c|c|c|c|}
\hline & & & & $\begin{array}{l}\text { Volume: } \\
\text { adult } \\
\text { dimensions }\end{array}$ & & $5.6 \mathrm{~mm}$ & & $70 \%$ \\
\hline \multirow[t]{2}{*}{8} & M & & & & & & & \\
\hline & $\mathbf{F}$ & & & & & & & \\
\hline \multirow[t]{2}{*}{9} & M & & & & & & & \\
\hline & $\mathbf{F}$ & $\begin{array}{l}(9.54) \text { Depth: } \\
\text { puberty onset }\end{array}$ & & & & & & \\
\hline \multirow[t]{2}{*}{10} & $\mathbf{M}$ & Width: $93.2 \mathrm{~mm}$ & & $\begin{array}{l}10.5) \\
\text { Height } \\
91.5 \% \\
(10.5) \\
\text { Intercanthal } \\
\text { width } \\
\text { maturation } \\
\end{array}$ & & & & \\
\hline & $\mathbf{F}$ & Width: $92.3 \mathrm{~mm}$ & & $\begin{array}{l}10.5) \\
\text { Height } 96 \%\end{array}$ & & & & $\begin{array}{l}(10-12) \\
\text { Puberty }\end{array}$ \\
\hline \multirow[t]{2}{*}{11} & M & $\begin{array}{l}(11.56) \quad \text { Depth: } \\
\text { Puberty Onset }\end{array}$ & Vertical: $51 \mathrm{~mm}$ & & & $\begin{array}{l}115.55 \\
\mathrm{~mm}\end{array}$ & & \\
\hline & $\mathbf{F}$ & $\begin{array}{l}(11.5) \quad \text { Depth: } \\
\text { Puberty Peak }\end{array}$ & & & & & & \\
\hline Age & Sex & Mandible & Maxilla & Orbits & \begin{tabular}{|l|} 
Cranial \\
Width
\end{tabular} & AFH & Forehead & Total Face \\
\hline \multirow[t]{2}{*}{12} & M & & $\begin{array}{l}\text { Maxillary Width: } \\
95 \% \\
\text { Strong Prediction } \\
\text { of Adult Size. } \\
\end{array}$ & & & & & $\begin{array}{l}(12-14) \\
\text { Puberty }\end{array}$ \\
\hline & $\mathbf{F}$ & $\begin{array}{|ll|}\text { Width Maturation. } \\
\text { Body } & \text { Height } \\
\text { Maturation. } & \\
\end{array}$ & $\begin{array}{l}\text { Maxillary Width: } \\
98 \% \text { Vertical } \\
\text { Maturation. } \\
\text { Strong Prediction } \\
\text { of Adult Size. }\end{array}$ & & & & & \\
\hline \multirow[t]{2}{*}{13} & $\mathbf{M}$ & \begin{tabular}{|l|} 
Width Maturation. \\
(13.4) $\quad$ Depth: \\
Puberty Peak
\end{tabular} & & & & & & \begin{tabular}{|l|}
$(13-15)$ \\
Final Size \\
Maturation.
\end{tabular} \\
\hline & $\mathbf{F}$ & Depth Maturation. & $\begin{array}{l}\text { Bizygomatic } \\
\text { Maturation. }\end{array}$ & & & $\begin{array}{l}\text { Maturatio } \\
\mathrm{n}\end{array}$ & & $\begin{array}{l}\text { Midfacial } \\
\text { Projection } \\
\text { Maturation. }\end{array}$ \\
\hline \multirow[t]{2}{*}{14} & $\mathbf{M}$ & & $\begin{array}{l}\text { Vertical } \\
\text { Maturation }\end{array}$ & & & & & \begin{tabular}{|l|} 
Midfacial \\
Projection \\
Maturation. \\
\end{tabular} \\
\hline & $\mathbf{F}$ & \begin{tabular}{|l|} 
Average Total \\
Growth Maturation
\end{tabular} & \begin{tabular}{|l|} 
Average Total \\
Growth \\
Maturation
\end{tabular} & & Maturation & & $\begin{array}{l}(14-16) \\
97 \%\end{array}$ & \\
\hline 15 & $\mathbf{M}$ & 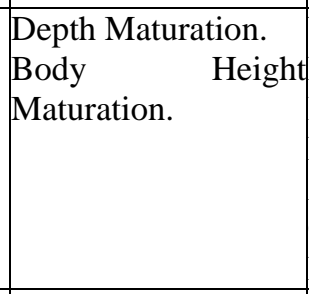 & \begin{tabular}{|l} 
Width \\
Maturation. \\
Bizygomatic \\
Maturation. \\
Average Total \\
Growth \\
Maturation \\
\end{tabular} & & \begin{tabular}{|l|}
$15-17)$ \\
Maturation
\end{tabular} & $\begin{array}{l}\text { Maturatio } \\
\mathrm{n}\end{array}$ & & \\
\hline Age & Sex & Mandible & Maxilla & Orbits & \begin{tabular}{|l} 
Cranial \\
Width
\end{tabular} & AFH & Forehead & Total Face \\
\hline (15) & $\mathbf{F}$ & & & & & & & \begin{tabular}{|l|} 
Total \\
Transverse \\
Growth \\
Maturation. \\
\end{tabular} \\
\hline \multirow[t]{2}{*}{16} & $\mathbf{M}$ & $\begin{array}{l}\text { Average Total } \\
\text { Growth Maturation }\end{array}$ & & & & & $\begin{array}{l}(16-17) \\
89 \%\end{array}$ & \\
\hline & $\mathbf{F}$ & & $\begin{array}{l}\text { Width } \\
\text { Maturation }\end{array}$ & & & & & \\
\hline
\end{tabular}




\begin{tabular}{|l|l|l|l|l|l|l|l|}
\hline 17 & $\mathbf{M}$ & $\begin{array}{l}\text { Depth: } 126.9 \mathrm{~mm} \\
\text { Body Height: } 52 \mathrm{~mm}\end{array}$ & & & & & $\begin{array}{l}\text { Total } \\
\text { Transverse } \\
\text { Growth } \\
\text { Maturation. } \\
(17-25) \\
\text { Final } \\
\text { Size } \\
\text { Maturation. }\end{array}$ \\
\hline & $\mathbf{F}$ & $\begin{array}{l}\text { Depth: } 117.3 \mathrm{~mm} \\
\text { Body Height: 46.9 } \\
\text { mm }\end{array}$ & & & & & \\
\hline $\mathbf{1 8}$ & $\mathbf{M}$ & & & & & & \\
\hline & $\mathbf{F}$ & & & & & & \\
\hline
\end{tabular}

Citation: A. Midori Albert, Amanda L. Payne, Sean M. Brady, Charissa Wright. Craniofacial Changes in Children-Birth to Late Adolescence. ARC Journal of Forensic Science. 2019 4(1): 1-19. http://dx.doi.org/ 10.20431/2456-0049.0401001

Copyright: (c) 2019 Authors. This is an open-access article distributed under the terms of the Creative Commons Attribution License, which permits unrestricted use, distribution, and reproduction in any medium, provided the original author and source are credited. 